This item was submitted to Loughborough's Research Repository by the author.

Items in Figshare are protected by copyright, with all rights reserved, unless otherwise indicated.

\title{
Applying Kolb's experiential learning cycle for laboratory education
}

PLEASE CITE THE PUBLISHED VERSION

PUBLISHER

(C) American Society for Engineering Education

VERSION

AM (Accepted Manuscript)

LICENCE

CC BY-NC-ND 4.0

REPOSITORY RECORD

Abdulwahed, Mahmoud, and Zoltan K. Nagy. 2009. "Applying Kolb's Experiential Learning Cycle for Laboratory Education”. figshare. https://hdl.handle.net/2134/5412. 
This item was submitted to Loughborough's Institutional Repository (https://dspace.lboro.ac.uk/) by the author and is made available under the following Creative Commons Licence conditions.

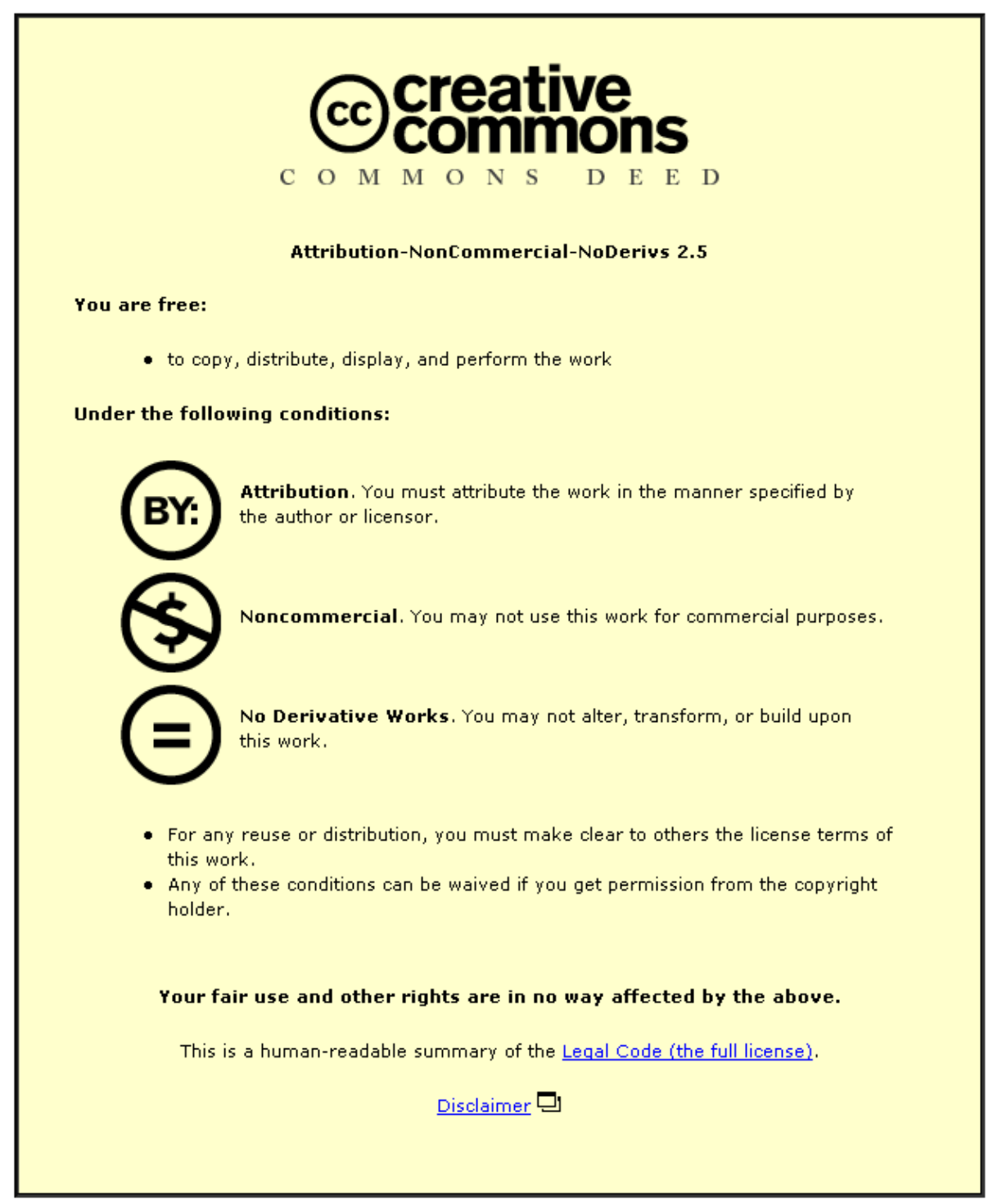

For the full text of this licence, please go to: http://creativecommons.org/licenses/by-nc-nd/2.5/ 


\section{Applying Kolb's Experiential Learning Cycle for Laboratory Education}

MAHMOUd ABDULWAHED

Engineering Center of Excellence in Teaching and Learning

Loughborough University

ZOLTAN K NAGY

Chemical Engineering Department

Loughborough University

\section{AbSTRACT}

This paper describes a model for laboratory education based on Kolb's experiential learning theory. The method is implemented using modern teaching technologies and a combination of remote, virtual, and hands-on laboratory sessions and have been applied to the teaching of the undergraduate process control laboratory at the Chemical Engineering Department at Loughborough University, United Kingdom. An argument that poor learning in the laboratory is due to insufficient activation of the prehension dimension of Kolb's cycle was suggested and verified, providing a pedagogical explanation. The quantitative analysis showed significant enhancement of the learning outcomes of the experimental group compared with the control group. Apart from the hands-on session, the proposed model involves additional activities, such as pre- and post-lab tests and virtual laboratory sessions, which are associated with Kolb's cycle to facilitate constructivist learning. The paper provides the first laboratory education model that builds thoroughly on Kolb's experiential learning theory.

Keywords: Kolb's experiential learning, laboratory engineering education, remote and virtual laboratories

\section{INTRODUCTION}

The importance of laboratory experience in engineering education curricula has been emphasized in a large number of science and engineering education articles (Feisel, 2005; Hofstein and Lunetta, 2004; Johnstone and Al-Shuaili, 2001; Kirschner, 1988; Ma and Nickerson, 2006). The essential role of laboratories can be correlated with the fact that engineering is, in general, an applied science that requires hands-on skills and involves elements of design, problem solving, and analytical thinking. Well designed laboratories during undergraduate engineering degrees may well improve these skills of the future engineers.

Engineering had been taught as a primarily hands-on subject up to the 18th century. However, engineering education has benefited from the advances in science and it began to embed deeper theoretical concepts by the end of the 19th century, especially in the U.S. schools initially (Feisel, 2005). Since then, the pedagogical emphasis in engineering education has been shifted more towards classroom and lecture-based education, and in many schools, less attention has been given to the laboratory education, particularly during the last 30 years (Hofstein and Lunetta, 1982; Hofstein and Lunetta, 2004; Feisel and Peterson, 2002). Wankat (2004) observed that only 6 percent of the articles published in the Journal of Engineering Education from 1993-2002 had "laboratory" as a keyword. Laboratory pedagogy has been recently reported to be a fertile arena of research for the coming years (Feisel and Rosa, 2005; Hofstein and Lunetta, 2004), especially in the context of the increasing need to make more use of the new developments in information and communication technology (ICT) for enhancing the laboratory education.

The impact of laboratory education on students' learning is often not recognized (Roth, 1994). One reason for rethinking the role of the laboratory in engineering and science education is the recent shift towards constructivist pedagogy in which the importance of knowledge gained via experience is emphasized. Furthermore, constructivist pedagogy places a larger role on student autonomy in the learning process. This is particularly important in light of the recent increase in the needs of industry for engineering graduates who are autonomous and equipped with good hands-on skills. Enhancing laboratory education can serve as a motivating factor toward an engineering career.

Despite the important role of laboratories in engineering education, several researchers have reported that the expected benefits of laboratories on students' learning are not achieved in most of the cases (Hofestein and Lunetta, 2004; Roth, 1994). In their literature review, Ma and Nickerson (2006) found that 100 percent of the articles concerning hands-on laboratories considered that labs should be platforms for facilitating conceptual understanding, and 65 percent considered that laboratories should also facilitate the design skills. However, constructing knowledge is a complex process which is often out of the timeframe of the planned laboratory sessions. Knowledge construction has four main phases according to Kolb's experiential learning theory (1984), including stimulation, reflection, abstraction, and experimentation. Meaningful learning is an iterative process requiring reflection (Hofestein and Lunetta, 2004). These practices are generally missing in the classical handson taught laboratories. Gunstone (1991) considers that laboratories which are taught in the classical way can barely be considered as platforms of knowledge construction, since students have less time to interact and reflect while they are busy with the technical and the operational side of the lab. Kirschner (1988) points out the main shortcomings in some of the hands-on laboratory sessions, including that students are often required to solve problems that are more difficult than their cognitive abilities, students are constrained with the short time periods the labs normally offer, and teachers assume 
that students will be able to overcome the problems in the assigned time (Kirschner, 1988). Kirschner also describes that classical labs are usually taught as one single demonstration due to economical and logistical reasons; however, forming and understanding concepts require repetition (Kirschener, 1988). There is a general consensus that laboratory work generates poor learning outcomes compared to the time, effort, and costs invested in laboratory education (Hofestein and Lunetta, 2004; Johnstone and A1-Shuaili, 2001; Kirschner, 1988; Ma and Nickerson, 2006). One possible reason for the poor learning outcomes is that engineering labs are very seldom designed based on well defined constructivist pedagogical models. One of the suitable pedagogical models for engineering education is Kolb's experiential learning framework. Kolb's experiential learning cycle is particularly suitable for engineering education which is an experiential field of science (Bender, 2001; Felder et al., 2000). Based on Kolb's theory, Moor and Piergiovanni (2003) justified the advantages of blending classroom theory with experiments. Kamis and Topi (2007) examined three hypotheses of pedagogical design for enhancing the problem solving in the field of networks subnettings. Two of them were based on Kolb's model while the third was based on the advance organizer technique (Ausubel, 1968). Bender (2001) explained a major reform of the courses taught at the Engineering Design department at the Technical University of Berlin using Kolb's theory and described the importance of incorporating the four dimensions of learning in the design of lectures. Lagoudas et al. (2000) restructured five core undergraduate engineering courses using Kolb's cycle as a pedagogical background for this process. They relied on computer software and simulations in their implementation of Kolb's theory (Lagoudas et al., 2000). Plett et al. (2006) redesigned three engineering courses building upon Kolb theories and the 4MAT system. The trial course (Introduction to Robotics) was very successful and led to a successful NSF grant proposal for curriculum design, in which they aim to redesign a series of systems courses based on the Kolb/4MAT pedagogical model. David and Wyrick (2002) assessed the learning styles of industrial engineering students over a ten-year period and used Kolb's experiential learning cycle as a pedagogical basis for designing learning experiences for the students. One key finding in their study was that providing balanced learning experiences to the students, based on the four stages of Kolb's cycle, had led to deeper learning and longer retention of information. Stice (1987) also implemented teaching strategies in the class that can accommodate all four stages of Kolb's cycle to improve the learning process for undergraduate students.

A thorough literature review on engineering laboratory design, in particular in the context of incorporating new technologies such as virtual and/or remote labs, reveals that the majority of papers are technically focused. This paper describes a new approach for laboratory education, which is underpinned by Kolb's experiential learning theory (Kolb, 1984). The method uses a combination of virtual, remote, and hands-on laboratory sessions and pre- and post-lab tests to maximize the information retention of students by activating the stages of Kolb's learning cycle. The approach has been used in the teaching of the second year undergraduate Process Control Laboratory in the Chemical Engineering Department at Loughborough University, United Kingdom. Qualitative and quantitative statistical analyses of the effectiveness of the method are presented. It is shown that the usually poor knowledge retention in laboratory education can be explained by the inefficient activation of the prehension dimension of Kolb's learning cycle. A methodology is proposed based on applying a Virtual Laboratory environment to provide a preparatory session before the hands-on laboratory to facilitate reflective preparation for the lab. The results show that significant enhancement of the laboratory learning process can be achieved by designing and applying a combination of in-class remote, virtual pre-lab, and hands-on laboratory sessions according to Kolb's experiential learning model. This paper embraces the Kolb's constructivist model as pedagogical basis of designing enhanced laboratory education.

\section{KOLB's EXPERIENTIAL LEARNING THEORY}

Kolb (1984) introduced his theory on experiential learning more than 20 years ago, which has been well accepted as an efficient pedagogical model of learning. Kolb's experiential learning theory provides clear mechanisms of teaching and learning design, which are strongly underlined with the constructivist view on the way people construct their knowledge. Kolb suggested that effective learners should have four types of abilities: (1) Concrete Experience ability (CE), (2) Reflective Observation ability (RO), (3) Abstract Conceptualization ability (AC), and (4) active Experimentation ability (AE).

Hence, the optimal learning takes place when learners have adequate balance of these four stages during their learning experience. According to Kolb, learning requires that individuals first should detect, depict, or grasp knowledge, and then a phase of construction should take place to complete the learning process. This construction is a transformation of the grasped knowledge into a mental model through experiencing this knowledge. Kolb proposed that the optimal learning would pass through a cycle of the Concrete Experience, Reflective Observation, Abstract Conceptualization, and Active Experimentation. This is called Kolb's experiential learning cycle and is shown schematically in Figure 1 . The vertical axis represents the knowledge grasping dimension, or the prehension dimension, by which knowledge can be grasped through Apprehension (the Concrete Experience extreme) or by Comprehension (the Abstract Conceptualization extreme), or by a mix of

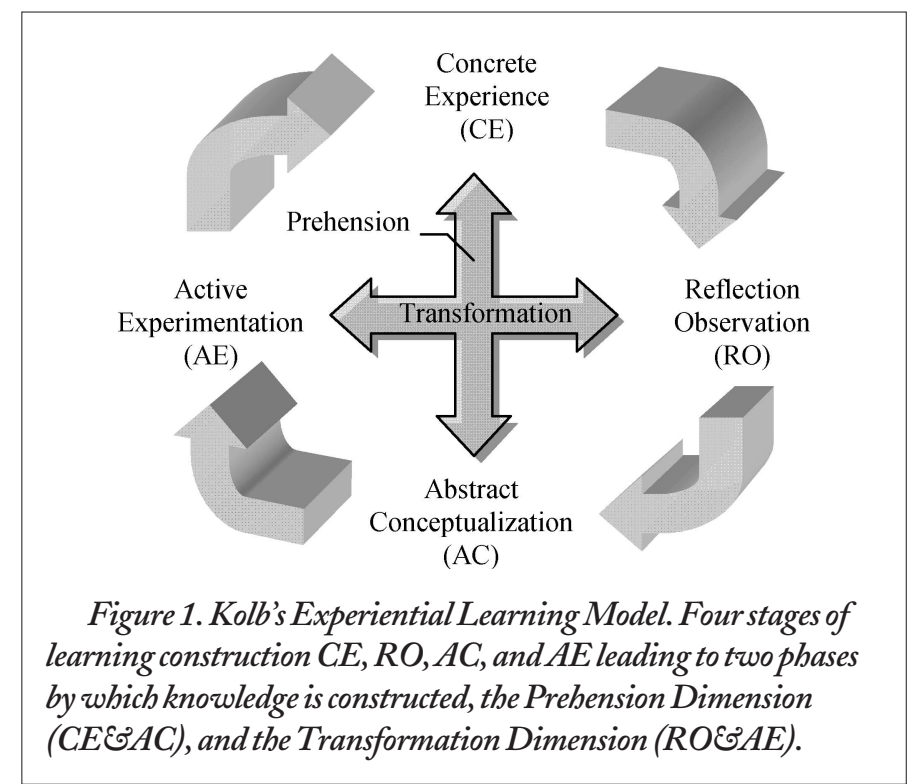


both. The horizontal axis represents the knowledge transformation or knowledge construction dimension. The construction can be done via Intention (the Reflective Observation extreme), or via Extension (Active Experimentation). Previous to this hypothesis, authors have not distinguished between grasping and transformation, combining them in one axis. Kolb's model distinguishes apprebension and comprehension as independent modes of grasping knowledge and intention and extension as independent modes of transforming experience. Furthermore he states that the four modes are equally important in contributing to the learning process, which is in disagreement with Piaget's (1978) opinion that comprehension and intention are superior processes. In a thoughtful look at the current traditional teaching methods in higher education, especially in Europe, one can easily realize that in many cases Piaget's model of comprehension-intention superiority is followed. These "traditional" teaching methods emphasize theory taught in classical classroom settings and reflection on this theory by written exams. In contrast, Kolb's experiential learning theory has strong implication for allowing balanced room for each mode, apprehension, comprehension, intention, and extension in the learning process. Hybrid combination of these elementary modes in the learning process produces higher level of learning.

During the laboratory session, students are mainly involved in the "Active Experimentation" stage of Kolb's cycle, because the emphasis is on doing the experiment. However, learning something from the experiment, or in other words, the transformation phase for constructing new knowledge through the experimentation, requires first the information to be grasped or depicted. In the case of close-ended laboratory sessions, the information that is grasped is mainly the experimental procedures and the theory behind the lab (AC of Kolb's cycle).

\section{Proposition}

In light of Kolb's experiential learning theory, a poor learning outcome of the laboratory session that has been frequently reported in the literature could be related to a weak activation of the prehension dimension before coming to the lab. Hence the lab session turns into an algorithmic following of the lab manual instead of actively constructing meaningful knowledge out of it.

In this paper it is proposed that using the virtual lab in a preparation session can lead to better activation of the prehension dimension in Kolb's cycle, which then yields a better activation of the transformation dimension. To test this assumption, a pedagogical experimental procedure was designed and applied in the second year Process Control Laboratory for Chemical Engineering students at Loughborough University, United Kingdom.

\section{VIRTUAL LABORATORIES IN EDUCATION}

Computer simulations became an integrated part of engineering education as early as the 1970s (Campbell, 1985; Gladwin, Margerison, and Walker, 1992; Gosman et al., 1977; Ingram et al., 1979; Kinzel et al., 1981; Laghari et al., 1990; Smith, 1976). Virtual laboratories (simulated versions of the hands-on labs) present a series of advantages, such as they are more cost-effective to implement and run, are not constrained by time or space, they are safe, etc. In science and engineering education virtual labs have emerged as complementary or alternative tools of the hands-on laboratory education. Raineri (2001) supplemented the hands-on laboratory on molecular biology with a simulated version available on the Web. The main aim of the simulated lab was to provide the students with the chance of repeating the experiments many times so that they can acquire higher level skills and techniques in data manipulation and interpretation, which are usually very difficult to develop in the usual three hour classical hands-on laboratory sessions. Using the simulated lab with the course for five years yielded a 5 percent increase in the final exam scores, and a dramatic decrease in the number of students who either failed or passed only with the minimum threshold (Raineri, 2001). However, Raineri stresses the importance of the hands-on lab, pointing out that the simulated lab is rather a supplement than a replacement. Very similar conclusions were reported by Ronen and Eliahu (2000). They used computer simulations software to offer a supplemental version of an electrical circuit design experiment. They found that 70 percent of the students in the experimental group benefited from using the simulation by enhancing their confidence and patience during the hands-on sessions. The students who did not benefit from the simulation were either those with very high conceptual capabilities for whom the software formed no additional aid in the task, or those with very low understanding of the topic and who showed no interest in improving.

Spicer and Stratford (2001) performed a qualitative study on the students' perception of replacing real field trips with simulated ones. The students showed very positive attitudes towards using the simulated field trip, but opposed the replacement of the real field trip with a simulated one. They valued using the latter as a pre- or postinstrument to be utilized before or after the real field trip.

After two years of combining computer simulations with handson laboratory activities in life sciences, McAteer et al. (1996) concluded that simulations have granted the students better conceptual understanding; however, there is still a need for the hands-on physical skills, emphasizing that both modes are important and they are not mutually exclusive.

Lindsay (2005) studied the impact of the access mode to the labs, i.e., hands-on, remote, or simulated, on the learning outcomes. The results of the statistical analysis suggested that each mode offers different learning outcomes, and adopting hybrid access modes would enrich the learning experience of the students.

Heise (2006) did a comparative study on students' performance in a digital logic lab, which was offered in both hands-on and simulated versions. Heise observed that students' motivation and interest increased dramatically during the hands-on lab compared to when the simulated experiments were used only.

There is general agreement that simulations cannot and should not always replace the hands-on labs; however, they can be effective assisting tools. Engum, Jeffries, and Fisher (2003) performed a comparative study on using a virtual catheter lab versus a real catheter lab. The study revealed that both groups of students who performed the real or the virtual lab demonstrated the development of adequate skills; however, the students preferred performing the real lab. Engum and his colleagues suggested that a combination of the two methodologies may enhance the students' satisfaction and skills acquisition level.

\section{A. Virtual Labs in Preparation Session}

Laboratory preparation can be conducted in many ways. For instance, students can be asked to prepare by reading the manual 
and developing an experimental procedure. Alternatively the lab manual preparation can be combined with using a simulated version of the lab (virtual lab). The lab manual plus virtual lab preparation can result in enhanced preparation due to many reasons.

According to the dual coding theory of information cognition, the human mind perceives and stores verbal and visual information through two distinct channels (Paivio, 1971). The implication on educational processes is that incorporating visual objects with verbal information can lead to better learning (Slavin, 2005). The virtual lab presents a suitable tool of visualizing the experimental rig in a simplified way and for showing the experimental plots.

The VARK learning styles model suggests that there are four main learning styles: visual, aural, read/write, and kinesthetic (VARK, 2008). Preparing from the lab manual could be suitable for those students who have strong read/write learning styles; however, combining the virtual lab with the lab manual in the preparation accommodates the students who have visual and kinesthetic learning styles, since the virtual lab is visualizing the experiment (visual style) and gives the students a chance of doing the experiment virtually (kinesthetic). The learning pyramid model (Weenk, 1999) suggests that information retention rates are different depending on the learning method ( 5 percent lecture, 10 percent reading, 20 percent audio/visual, 30 percent demonstration, 50 percent discussion group, 75 percent practice by doing, 90 percent teaching others). Virtual lab provides a chance for doing the experiment and hence resulting in a much higher knowledge retention rate than using the lab manual alone.

One key shortcoming of the classical hands-on laboratory teaching is the poor conceptual learning outcome due to time constraints, lack of repetitions, and the high cognitive load (Hofestein and Lunetta, 2004; Johnstone and Al-Shuaili, 2001; Kirschner, 1988; Ma and Nickerson, 2006, Roth, 1994). In general, supplementing the hands-on labs with a virtual version has been found useful, but in most cases, students do not believe that the virtual lab can be an alternative to hands-on labs (Engum, Jeffries, and Fisher, 2003; McAteer et al., 1996; Raineri, 2001; Ronen and Eliahu, 2000; Spicer, 2001). Offering the students a pre-lab session for which they prepare using the lab manual and the virtual lab may assist in overcoming some shortcomings of the hands-on labs (Gillet et al., 2005; Gurkan, Mickelson, and Benhaddou, 2008). Additionally, the use of the virtual labs provides an ideal framework for inducing reflections during the preparation session. According to Kolb's model, these reflected the conceptualization and learning already present during the preparation for the lab.

\section{Case Study: Process Control Laboratory}

The Process Control Laboratory is part of the second year Instrumentation, Control, and Industrial Practice module at the Chemical Engineering Department at Loughborough University, UK. The experimental rig for the hands-on process control lab was designed using a surge tank system. Figure 2 shows a generic schematic diagram of the hands-on experimental rigs. The laboratory is a compulsory part of the module designed for undergraduate engineering master's (MEng), bachelor's (BEng), and bachelor's of science (BSc) programmes in Chemical Engineering at Loughborough University. The lab aims to introduce students to the principles of control engineering, such as the main components and instruments of a feedback loop, the concepts of open-loop control, feedback control, proportional-integral-derivative (PID) control, and PID controller tuning.

The hands-on laboratory consists of two sessions, 3 hours each in duration. The sessions are scheduled for two consecutive weeks. In the first week the students are introduced to the elements of typical feedback loops such as sensors, actuators, controllers, and processes. The main objectives of the first session are: (i) calibration of the level sensor and (ii) calibration, hysteresis detection, installed characteristics, and relative resistance of the control valve.

During the second week, students are introduced to control engineering concepts, the main objectives being: (i) to develop an appreciation of automatic control vs. manual control; (ii) to obtain a qualitative grasp of the differences among, proportional controller $(\mathrm{P})$, proportional-integral controller $(\mathrm{PI})$, and proportional-integralderivative controller (PID); (iii) to develop rules for control

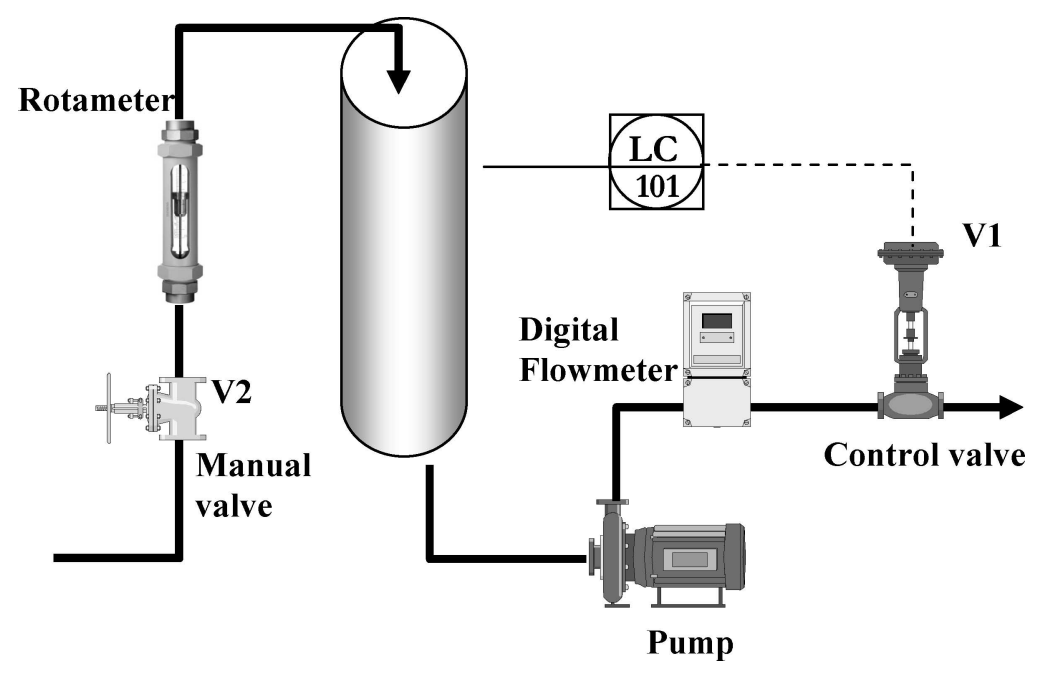

Figure 2. Schematic of the Process Control Lab Test Rig. The lab was designed to mimic an industrial plant. It aims to introduce students to the basic elements of instrumentation and control, and to develop qualitative skills of tuning PID controllers. 


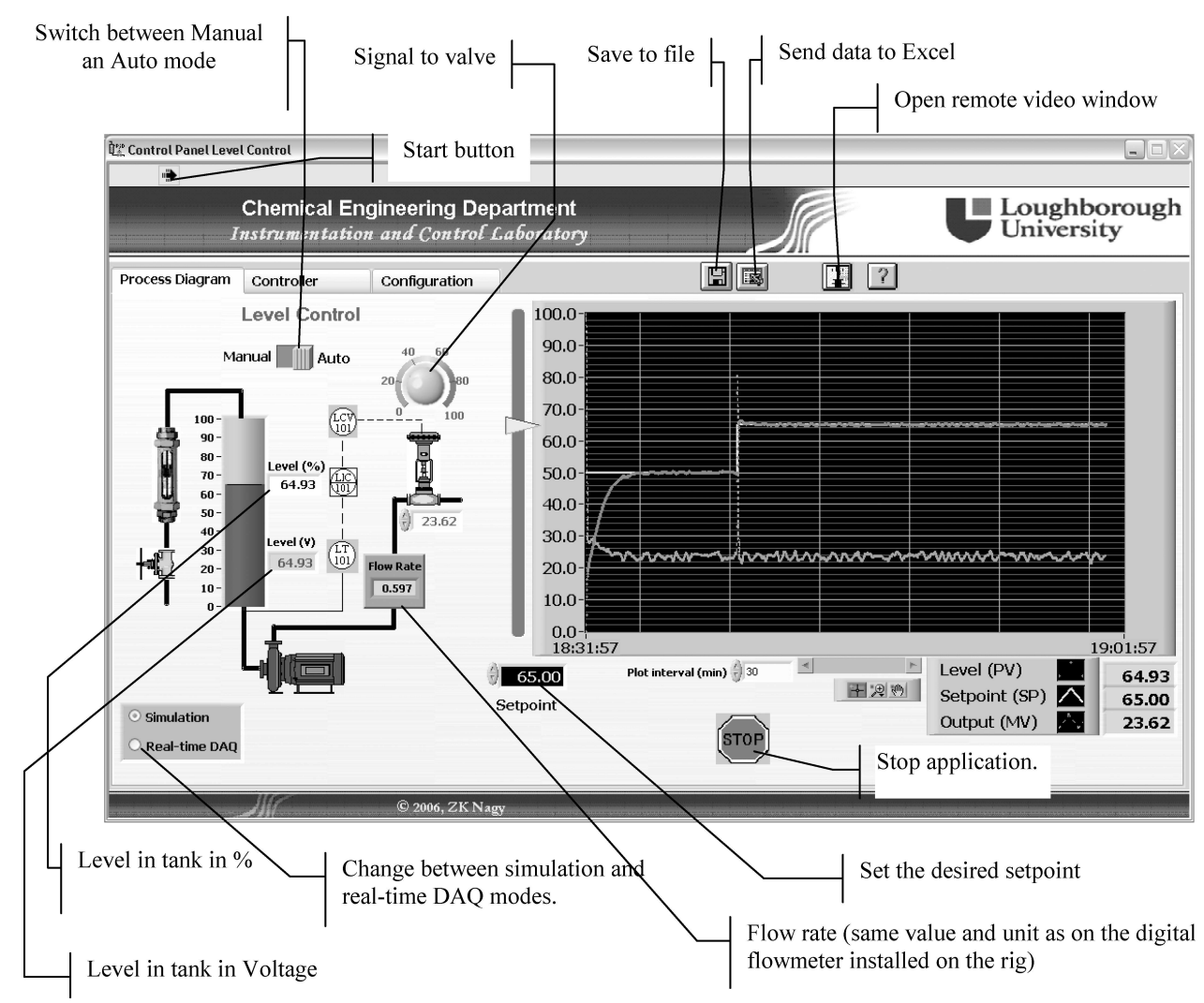

Figure 3. The Process Control Lab Virtual and Remote Version Interface. The GUI was designed to mimic the hands-on lab when working in the simulation mode. In case of proximal connection, the GUI provides an interface for data acquisition, instruments manipulation, and PID control tuning. In cases of remote connection, it provides video transmission of the rig.

structure selection based on the observed qualitative information; and (iv) to perform automatic controller tuning.

A virtual version of the lab has been developed using National Instrument's software environment, LabVIEW, and it was made available to students for download. A sample snapshot of the operator interface is presented in Figure 3. The Process Control Virtual Laboratory allows students to perform all experiments in a simulation mode using an interface identical to the real operator interface in the laboratory.

A remotely operated version of the lab was also developed and used in the classroom to illustrate the theoretical concepts on reallife experiments. Both virtual and remote operation modes of the lab were integrated in one software package. The software also provides real-time video transmission for creating the feeling of "telepresence" when remote lab is in operation. Software and hardware were based on National Instrument LabVIEW (version 8.0) and NI USB-6000 series USB data acquisition (DAQ) device. The software interface is shown in Figure 3, and it is available for download at http://www.ilough-lab.com.

The aim of developing virtual and remote modes of the process control lab was to enrich the laboratory education by offering different access modes that enable maximum utilization of the process control lab during the module. For instance, the virtual lab offers the students an ideal way of practicing the laboratory procedure before coming to the hands-on session, while the remote lab enables the teacher to broadcast the lab operation live in the classroom for stimulating the students or for explaining the application of theory in practice. Remote access to the hands-on laboratory also enables interested students to do further inquiry related to the hands-on experiment from home or anywhere with an internet connection. Such remote connections may eliminate many logistical problems associated with conducting hands-on experiments in the university lab, such as specific lab opening hours, or safety and supervision problems related to the students being physically present in the lab.

\section{Methodology for Pedagogical EFFECTIVENESS MEASUREMENT}

\section{A. Selection of the Control and Experimental Groups}

There were about 70 students registered for the class. In the laboratory, six experimental rigs were used, with students working in groups of 2 or 3 . Students were divided into four session groups, each of which consisted of 16-18 students. Each group used the rig for two consecutive weeks to complete the experiments. The lab teaching spread over 8 weeks from the academic week 2 until the academic week 9 in the autumn semester of the 2007-2008 academic year. In week one an introductory lecture was organized in a classroom to all students where the experiment was described. In this session the laboratory was "brought into the classroom" by using the remote laboratory mode aiming to stimulate the students' interest in the lab. A pre-lab preparation session was also organized for part of the groups, during which students came to the computer room and worked on the virtual laboratory software following the procedure from the lab manual while working under minimal supervision. These pre-lab sessions (treatment) were applied to 
Groups 3 (G3) and 4 (G4), whereas Groups 1 (G1) and 2 (G2) had no treatment.

To guarantee equivalence as much as possible among the four groups, students were distributed evenly based on their percentage average in the previous academic year (the averages of the groups were, $\mathrm{G} 1=64.2$ percent, $\mathrm{G} 2=63.6$ percent, $\mathrm{G} 3=63.1$ percent, and $\mathrm{G} 4=63.7$ percent). In the British educational system, percentage averages are used in the final evaluations and the assignment of grades (A, B, etc) is subjective. The convention used in the Chemical Engineering Department at Loughborough University is generally to use the grade $\mathrm{A}$ for an average above 70 percent, $\mathrm{B}$ for an average between 60 percent and 70 percent, $\mathrm{C}$ for average between 50 percent and 60 percent, etc. Exams are usually designed with the aim to have an overall average between 60 percent and 70 percent, hence the groups represent average levels. The groups G1 and G2 represented the control group, whereas G3 and $\mathrm{G} 4$ were the experimental group.

\section{B. Logistical and Ethical Issues in the Experimental Design}

Logistical and ethical aspects of the experimental design are important to analyze to understand the experimental data. To make the pre-lab preparatory sessions compulsory, would require changes in the course structure requiring approval by the departmental and university teaching committees, and can violate generic recommendations related to the number of contact hours within a module. The extra hours required for the preparatory session would be possible only by reducing the number of lectures or problem classes. Not making the virtual laboratory software available to the control group would have raised ethical issues related to the discrimination in using teaching aids for parts of the class. Partially this was also the reason why minimal supervision and help was offered in the preparatory session. To overcome the logistical and ethical constraints, the experiments were designed so that no pre-lab preparatory sessions were scheduled for groups G1 and G2. However, they were asked to prepare for the lab. The intention in the experiments was that the control group would prepare by reading the manual and the experimental group by using the virtual lab and the manual. However to eliminate ethical issues, the lab manual and the virtual lab software were made available for students to download and use in their preparation. In the questionnaires, students from the control group had to answer the questions whether and how long they prepared from the manual and this data was used in the evaluation. Non-compulsory pre-lab sessions were scheduled for the G3 and G4 students. These were time-tabled internally trying to eliminate conflicts with the students' other duties as much as possible.

About 8-10 students of each G3 and G4 responded to the request of attending the preparation session each time, forming the experimental group. The average mark of the experimental group was 66.7 percent. Students from Groups 1 and 2 formed the control group with a group average of 63.8 percent (only 2.9 percent less than for the experimental group).

Figure 4 illustrates the methodology used for the pedagogical experiment, with $\mathrm{X}$ representing the equivalent groups (control and experimental before treatment) and $\mathrm{Y}$ and $\mathrm{Yt}$ represents the results from the control and the experimental groups after treatment, respectively.

For the evaluation of the statistically significant difference between the control and the experimental group (if any) in response to the treatment the null hypothesis was used (Conover, 1998). The

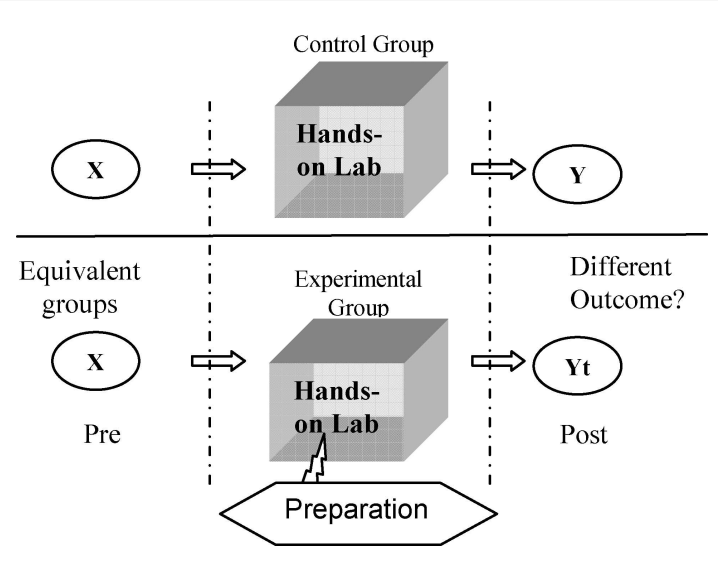

Figure 4. Conceptual model of the pedagogical experimentation methodology. The control group had no treatment, while the experimental group was exposed to a preparation session with the virtual laboratory.

null hypothesis in this case states that, "There is no statistically significant difference in the learning outcomes between the control group and the experimental group due to using the virtual lab in a pre-lab preparation session."

The Mann-Whitney non-parametric test (Conover, 1998) was used for accepting or rejecting the null hypothesis. According to this approach the null hypothesis is rejected (meaning that there was a statistically significant difference between the data) if the significance value $(\sigma)$ of the test is less than 0.05 .

\section{Verification Stages for the Proposition}

The verification was divided into two main parts: (1) verifying that the virtual lab can lead to enhanced activation of the prehension dimension, and (2) verifying that this leads to better activation of the knowledge transformation dimension.

For the prehension dimension activation verification, a pre-lab test was designed and was conducted just before starting the handson session. The pre-lab tests were given to students in both weeks 1 and 2. The questions from a sample pre-lab test used in week 1 are given in the Appendix. The statistically significant differences between the answers of the students from the control and the experimental groups would indicate that a pre-lab session with virtual lab played a role in grasping information needed for the hands-on laboratory session.

\section{Analysis of Knowledge Grasping}

Questions Q1 and Q2 of the Week 1 pre-lab test were strongly related to the hands-on laboratory session. In these questions, students were asked to develop an experimental procedure that they will follow for calibrating and deriving the characteristics of the level sensor of the tank and the control valve that controls the outflow rate of the tank, respectively. Questions Q3-Q7 were mainly designed to test relevant general knowledge of the students that they may have gathered through the lectures, from the remote lab demonstrations that were conducted in the classroom, or by reading the lab manual. The results of the evaluation of the pre-lab test are shown in Table 1. Using the Mann-Whitney test, the exact significance value of Q1 and Q2 were smaller than 0.05 indicating that the null hypothesis can be rejected, hence there is indeed strong 


\begin{tabular}{lcc}
\hline Question & $\begin{array}{c}\text { Exact significance, } \\
\text { "Sigma"(Mann- } \\
\text { Whitney U test) }\end{array}$ & $\begin{array}{c}\text { Means \% } \\
\text { (Experimental / } \\
\text { Control) }\end{array}$ \\
\hline Q1 & 0.002 & $73.9 / 40.0$ \\
Q2 & 0.002 & $55.3 / 21.7$ \\
Sum Q3 to Q7 & 0.166 & $72.3 / 58.2$ \\
\hline
\end{tabular}

Table 1. Pre-lab test results of week 1. Number of samples (Experimental/Control) was 18/30.

statistical evidence that exposing the students to a preparatory session using the virtual laboratory has led them to an overall enhanced grasp of the procedural tasks needed for performing the lab. This demonstrates that a better activation of the prehension dimension has occurred due to the virtual lab preparatory session. The lower mean of the control group students is related to the fact that those students never or poorly prepared for the lab (all students were asked to prepare for the lab; the software and the lab manual were available to download from the $\mathrm{Web})$. Poorer results were shown when students had read only the manual and did not experience the procedure with the virtual lab. The difference between the control and the experimental groups is less significant $(\sigma=0.116>0.05)$ for the questions Q3 to Q7 though the average mean is still higher for the experimental group.

The level sensor calibration procedure was relatively easier than the procedure for the control valve calibration. This may explain the higher mean of Q1 compared to Q2. The pre-lab test of Week II revealed a similar outcome where the mean of the experimental group was higher for the control group. The statistical significance was smaller than the threshold of $0.05(\sigma=0.041)$ allowing to reject the null hypothesis. This shows that students of the experimental group have better activation of the prehension dimension of Kolb's cycle because they could grasp knowledge needed for the hands-on lab operation via the virtual lab that was used in a pre-lab session.

\section{E. Analysis of the Knowledge Transformation}

To verify that better activation of the prehension dimension would lead to better knowledge transformation into mental models (Kolb, 1984) after the hands-on lab session, post-lab tests were conducted directly after the students had finished their experiments.

Table 2 shows the results of the analysis of the post-lab test. In question Q1 of the Week 1 post-lab test, students were asked to create a qualitative plot of the level sensor characteristic curve based on their observations and the data they had collected during the experiment. The level sensor characteristic is represented by a simple linear curve with no hysteresis. The students' answers were rather close for both the experimental and the control groups. The exact significance value for Q1 was 0.302 which is larger than the threshold of 0.05 indicating that there is no statistically significant difference between the control and the experimental groups. In question Q2, students were asked to plot the control valve characteristic, which is nonlinear and shows hysteresis. A significantly larger portion (more than double) of the experimental group students could distinguish these features (which required a higher ability of indepth analysis) whereas fewer of the control group students could discover the hysteresis. The statistical significance value of Q2 is

\begin{tabular}{lcc}
\hline Question & $\begin{array}{c}\text { Exact Significance } \\
\text { (Mann-Whitney U } \\
\text { test) }\end{array}$ & $\begin{array}{c}\text { Means \% } \\
\text { (Experimental/ } \\
\text { Control) }\end{array}$ \\
\hline Q1 & 0.302 & $90.6 / 72.8$ \\
Q2 & 0.025 & $76.7 / 59.2$ \\
Q3 & 0.257 & $45.5 / 36.2$ \\
Q4 & 0.498 & $42.7 / 38.0$ \\
Q5 & 0.847 & $50.5 / 49.7$ \\
Q6 & 0.892 & $49.8 / 50.4$ \\
Q7 & 0.034 & $64.7 / 39.5$ \\
Q8 & 0.026 & $65.8 / 38,0$ \\
Q9 & 0.543 & $44.9 / 44.7$ \\
Q10 & 0.211 & $35.8 / 33.2$ \\
Sum Q1 to Q10 & 0.031 & $56.9 / 44.5$ \\
\hline
\end{tabular}

Table 2. Post-lab test results of week 1 (number of samples (Experimental/Control) was 18/32).

0.025 . This value is smaller than the threshold of 0.05 indicating a high probability ( 97.5 percent) that the higher score is not by chance, hence the null hypothesis can be rejected. For the other questions (Q3-Q6, Q9 and Q10), which are rather general, students from the control and the experimental group showed close outcome.

Questions 7 and 8 were purely conceptual, testing the students' understanding of open and closed loop systems. Students from the experimental group performed much better overall in these questions than students from the control group (see Table 2). It deserves mentioning that the simulation of the control valve in the virtual lab is not identical to the real behavior of the physical control valve in the test rig. The simulated control valve has linear characteristics and no hysteresis, hence these features were not observed by the experimental group students in the preparation session. Nevertheless, they showed higher ability of detecting these features than students from the control group. The statistical test of the in-depth question of Week 2 post-lab test also revealed acceptable significance for rejecting the null hypothesis (exact significance was $0.013<0.05$ ).

These results provide evidence that students who had better activation of the prehension dimension prior to the lab session had more in depth learning during the hands-on lab session. In other words, the transformation of knowledge through the lab experience into mental models (Kolb, 1984) has been more successful for students who worked on improving their prehension dimension. This also indicates that constructivist higher order learning in the handson lab session can be improved by more activation of the other stages of the Kolb's experiential learning cycle.

A different behavior was also observed during the laboratory sessions in the case of the experimental group students compared to the control group students. The former showed more interest in the hands-on lab session and insisted more on answering the pre- and post-lab tests compared to the control group students. Groups were informed that the pre- and post-lab tests were voluntary and were not included in the lab or the course final marks.

Kolb's experiential learning theory offers educators a pedagogical framework for designing their courses and contextualizing specific 
activities that lead to enhanced learning outcomes. The design can be on a large scale, such as a whole degree design, or on a smaller scale, such as the design of learning objects or a laboratory curriculum. Kolb suggests that optimal learning happens through transformation of knowledge into mental models. The transformation is done through reflective observation $(\mathrm{RO})$ and active experimentation (AE). However, a necessary condition for such transformation (or construction) of knowledge is that this knowledge should be grasped first. Knowledge depiction occurs via Concrete Experience (CE) or Abstract Conceptualization (AC). A reasonable balance among the four stages leads to optimal learning outcomes according to Kolb. In classical laboratories, the $\mathrm{AE}$ is the main active stage, which may give an explanation of poor learning outcomes during the laboratory learning phase and lead to propose additional laboratory activities that would enhance the other learning stages in Kolb's cycle. In the next section different laboratory activities and their contributions to Kolb's learning stages are discussed and a novel model for conducting laboratory education is proposed in the framework of the pedagogical experiential learning theory.

\section{An IMPlementation Proposal of Kolb's CYCLE FOR LABORATORY EDUCATION}

During the introductory lecture of the Instrumentation and Control module, students were introduced to the lab using a PowerPoint presentation and the lab was operated remotely in the classroom with the aim of providing a realistic feeling (telepresence) to students and stimulating them towards conducting the lab. This lecture structure is in correlation with the Concrete Experience stage of the Kolb's cycle. At the end of the semester in the module questionnaires, students were asked whether this stimulated their interest in the lab. A significant portion, 80.6 percent, of the students answered "Yes".

One of the lectures was devoted to PID control. In this lecture the theoretical background of the PID control approach was explained and the main features of the control algorithm were illustrated by using the remote lab in the classroom. Again, a significant portion of students, 78.1 percent, found this combination useful in understanding the theory which enhanced the Abstract Conceptualization part of the Kolb's cycle.

Well designed pre-lab test questions or preparatory sessions with the virtual laboratory will help students in contextualizing the laboratory objectives and assist in realizing the Concrete Experience stage. The use of the virtual lab and the design of reflective questions facilitate reflection, enhancing the Reflective Observation stage.

Well designed post-lab test questions give the students a chance to reflect over their experience in the lab session. These questions must be designed to help with the implementation of a meaningful model of the knowledge in their memory based on the lab session experience. This also helps to enhance the Reflective Observation stage. Putting the pre- and post-lab testing in the context of laboratory education will urge the students to prepare well which enhances the Active Conceptualization stage.

According to Kolb, constructivist learning occurs in a cyclic spiral way. The optimal learning happens when all four phases of the learning cycle are activated. As the first cycle ends by transferring knowledge into mental (or theoretical) model through experience, a further higher order cycle can be started for constructing higher order knowledge, and so on. Therefore, it is an important objective of engineering education, in particular, laboratory education, to motivate students towards higher levels of learning or experimentation. In the last lecture of the course, we surveyed the students' opinion about the lab. One of the questions on the questionnaire was: "Would you like the idea of conducting post-lab real experimentation through the Internet (i.e., from your home PC) after the lab for enhancing your report or testing further ideas?" The possible answers were on a scale from 1 (not at all) to 6 (very much). The responses of the two groups differed considerably. The average of the control group is 4.19/6 while the average of the experimental group is $5.27 / 6$. The Mann-Whitney non parametric test gives the exact significant value of 0.027 , which is smaller than 0.05 hence the null hypothesis can be rejected. Figure 5 shows the students' answer distributions. This demonstrates again that an enhanced activation of the prehension dimension of Kolb's cycle has a statistically significant impact on motivating students towards further inquiry and experimentation; therefore providing a better constructivist experience for laboratory education.

\section{$\square$ Control Group Experimental Group}

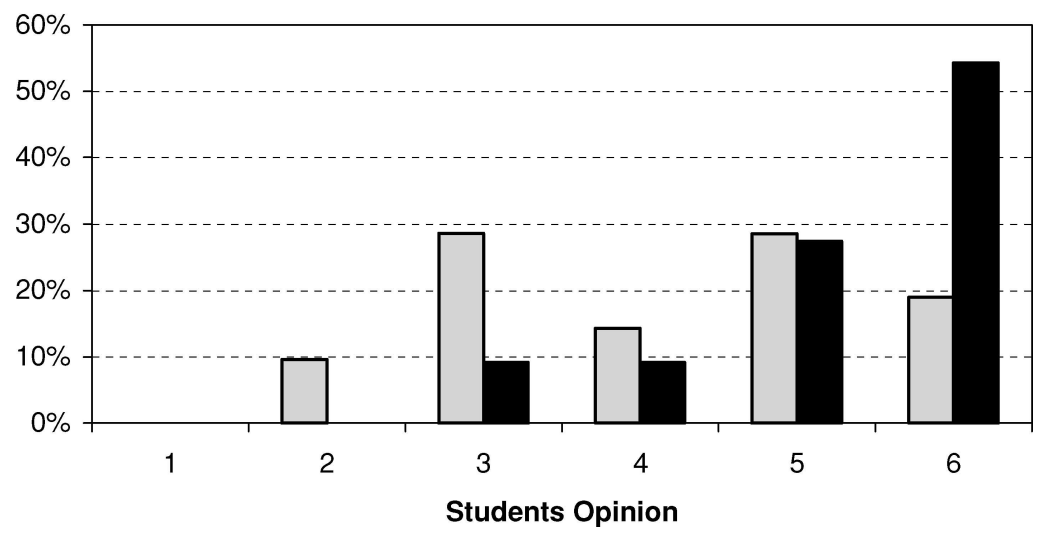

Figure 5. Experimental group students willingness of conducting further experimentation after the hands-on lab session (" 1 " = not at all, "6"= very much). 


\begin{tabular}{ll}
\hline Activity & Mapping to Kolb's Cycle \\
\hline Remote experimentation in the classroom & Concrete Experience, Abstract Conceptualization \\
Pre-lab test & $\begin{array}{l}\text { Concrete Experience, Reflective Observation, } \\
\text { Abstract Conceptualization }\end{array}$ \\
Post-Lab test & $\begin{array}{l}\text { Reflective Observation, Abstract } \\
\text { Conceptualization }\end{array}$ \\
Hands-on session & Active Experimentation, Abstract \\
& Conceptualization, Reflective Observation \\
Virtual Lab & Reflective Observation, Active \\
& Conceptualization, Active Experimentation \\
Post-Lab Remote Experimentation & Experimentation, and Higher order cycle of \\
& learning \\
\hline
\end{tabular}

Table 3. Kolb's cycle mapping for laboratory education.

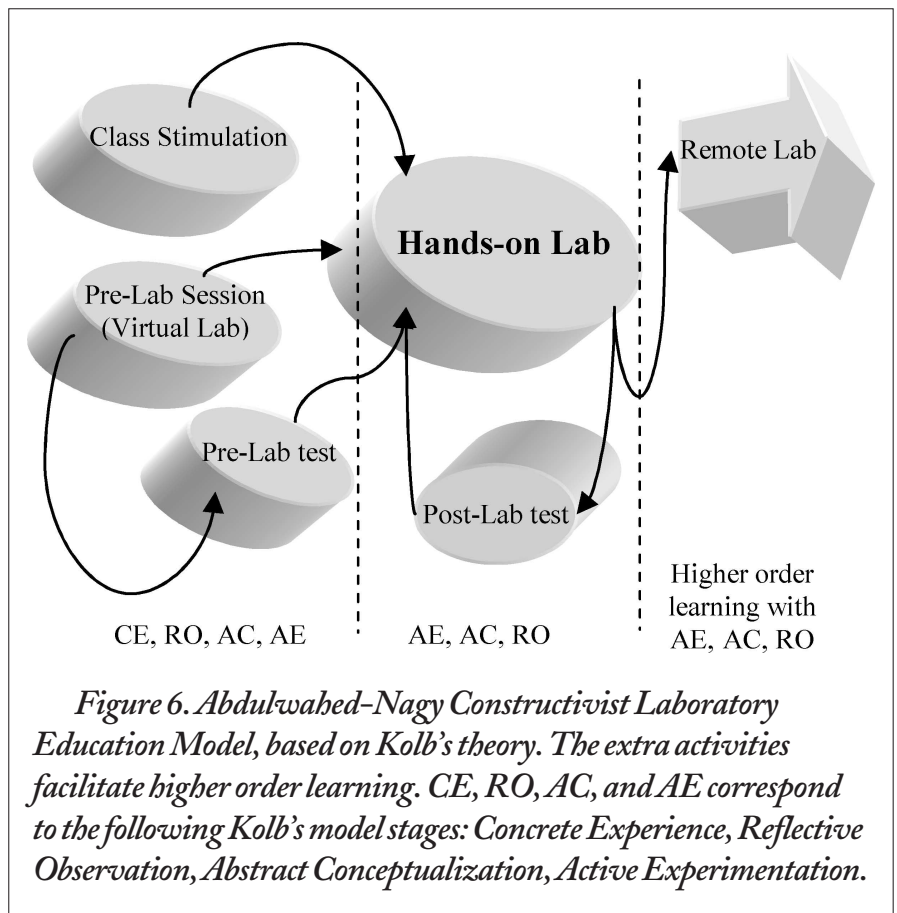

Remotely operated labs offer the chance to interested students for flexible further investigation and experimentation, i.e., they offer the possibility of higher order learning. This additional activity may involve additional theory investigation (Abstract Conceptualization), Active Experimentation, and Reflective Observation. Remote labs offer the students a chance to repeat the experiment and have further reflection of their hands-on session (Reflective Observation).

The virtual lab also offers a similar opportunity; however, the fundamental difference between the virtual lab and the hands-on or remote lab is the belief factor. The question related to the students' opinion about replacing the hands-on lab with the virtual lab resulted in 91.2 percent of the students rejecting this idea.

In the laboratory session, students are mainly immersed in the Active Experimentation stage of Kolb's cycle. Poor outcome of laboratory education can be correlated with the poor balance of the other stages of Kolb's experiential learning cycle, since little attention is normally paid to laboratory activities that can lead to constructivist learning during the hands-on session. The results of the pedagogical experimentation shown in this paper indicate that modifications can be introduced to the teaching methodology according to which classical hands-on laboratories are taught. These modifications, with the aim to enhance constructivist learning, are suggested in the context of Kolb's experiential learning cycle and are implemented using recent advances in information and communication technologies. The mapping of the different elements of the laboratory education system to Kolb's cycle is proposed in Table 3. Figure 6 shows a conceptual model of the constructivist laboratory based on Kolb's experiential learning cycle.

\section{CONCLUSIONS}

In this paper, the learning outcomes of the laboratory session are corroborated in the context of the well known pedagogical theory, Kolb's experiential learning cycle. A proposition is introduced that considers that the often poor learning outcome of the laboratory session is mainly due to weak activation of the prehension dimension of the learning cycle, before coming to the lab. The pedagogical experiments based on combined application of pre- and post-lab tests and the three dimensional laboratory (application of the combination of hands-on, virtual, and remote experiments) have provided statistical evidence of the proposition. In particular, introducing the virtual lab in the pre-lab preparation session has lead to considerable improvement in the conceptual understanding of the students during the hands-on lab session. It also helped to reduce the cognitive load of students. The results demonstrate that designing engineering laboratory education based on well-developed pedagogical theory can lead to better learning outcomes. Based on the pedagogical experiments, a novel model of laboratory education was introduced that has its pedagogical background in the experiential learning theory of Kolb. An algorithm of implementing Kolb's cycle utilizing virtual and remote modes of the hands-on lab, as well as, by introducing additional lab activities has been proposed.

\section{ACKNOWLEDGMENT}

Partial financial support by the Engineering Center of Excellence in Teaching and Learning (engCETL), Loughborough University, UK, and by The Higher Education Academy, Engineering Subject Centre, UK, mini-project are gratefully acknowledged. 


\section{REFERENCES}

Ausubel, D.P., and D. Fitzgerald. 1962. Organizer, General background, and antecedent learning variables in sequential verbal-learning. Journal of Educational Psychology 53 (6): 243-49.

Bender, B. 2001. Concepts for purposive and motivational teaching and learning in engineering design courses. International Journal of Engineering Education 17(4-5): 336-41.

Campbell, D.R. 1985. Interactive graphics software for an undergraduate course in digital signal processing. Computers $\mathcal{E}^{2}$ Education 9 (2): 79-86.

Conover, W.J. 1998. Practical nonparametric statistics. 3rd ed. Hoboken, NJ: John Wiley.

David, A., P.E. Wyrick, and L. Hilsen. 2002. Using Kolb's Cycle to round out learning. In Proceedings of the 2002 American Society for Engineering Education Annual Conference. Montréal, Quebec, Canada.

Engum, S.A., P. Jeffries, and L. Fisher, 2003. Intravenous catheter training system: Computer-based education versus traditional learning methods. The American Journal of Surgery 186 (1): 67-74.

Feisel, L.D., and G.D. Peterson. 2002. A colloquy on learning objectives for engineering education laboratories. In Proceedings of ASEE Annual Conference E'Exposition: Vive L'ingenieur! Montréal, Quebec, Canada.

Feisel, L.D., and A.J. Rosa. 2005. The role of the laboratory in undergraduate engineering education. Journal of Engineering Education 94 (1): 121-30.

Felder, R., D. Woods, J. Stice, and A. Rugarcia. 2000. The future of engineering education: II. Teaching methods that work. Chemical Engineering Education 34 (1): 26-39.

Gary, L., and J.A. Kinzel. 1981. The impact of computer graphics on mechanical engineering education at The Ohio State University. Computers EंEducation 5 (4): 275-87.

Gillet, D, A.V. Nguyen Ngoc, and Y. Rekik. 2005. Collaborative webbased experimentation in flexible engineering education. IEEE Transactions on Education 48 (4): 696-704.

Gladwin, R.P., D. Margerison, and S.M. Walker. 1992. Computer-assisted learning in chemistry. Computers E Education 19 (1-2): 17-25.

Gosman, A.D., B.E. Launder, F.C. Lockwood, and G.J. Reece. 1977. Computer assisted teaching of fluid mechanics and heat transfer. Computers $\Xi$ Education 1 (3): 131-39.

Gunstone, R.F. 1991. Reconstructing theory from practical experience. In Practical science, ed. B. Woolnough, 67-77. Milton Keynes: Open University Press.

Gurkan, D., A. Mickelson, and D. Benhaddou. 2008. Remote laboratories for optical circuits. IEEE Transactions on Education 51 (1): 53-60.

Heise, D. 2006. Asserting the inherent benefits of hands-on laboratory projects vs. computer simulations. Journal of Computing Sciences in Colleges 21 (4): 104-10.

Hofstein, A., and Lunetta, V.N. 1982. The role of the laboratory in science teaching: neglected aspects of research. Revierw of Educational Research 52(2): 201-217.

Hofstein, A., and V.N. Lunetta. 2004. The laboratory in science education: Foundations for the twenty-first century. Science Education 88 (1): $28-54$.

Ingram, D., C.J. Dickinson, L. Saunders, M. Sherriff, R. Bloch, G. Sweeney, and K. Ahmed. 1979. Application of a pharmacokinetic simulation program in pharmacy courses. Computers E Education 3 (4): $335-45$.

Johnstone, A.H., and A. Al-Shuaili. 2001. Learning in the laboratory; some thoughts from the literature. University Chemistry Education 5: $42-51$.
Kamis, A., and H. Topi. 2007. Network subnetting: An instance of technical problem solving in Kolb's experiential learning cycle. In Proceedings of the 40th Annual Hawaii International Conference on System Sciences. Waikoloa, HI.

Kirschner, P.A. 1988. The laboratory in higher science education, problems, premises, and objectives. Higher Education 17 (1): 81-90.

Kolb, D.A. 1984. Experiential learning: Experience as the source of learning and development. Englewood Cliffs, NJ: Prentice-Hall.

Laghari, J.R., J.L. Suthar, and S. Cygan. 1990. PSPICE applications in high voltage engineering education. Computers $\mathcal{E}^{2}$ Education 14 (6): 455-62.

Lagoudas, D.C., J.D. Whitcomb, D.A. Miller, M.Z. Lagoudas, and K.J. Shryock. 2000. Continuum mechanics in a restructured engineering undergraduate curriculum. International Journal of Engineering Education 16 (4): 301-14.

Lindsay, E.D., and M.C. Good. 2005. Effects of laboratory access modes upon learning outcomes. IEEE Transactions on Education 48 (4): 619-31.

Ma, J., and J.V. Nickerson. 2006. Hands-on, simulated, and remote laboratories: A comparative literature review. ACM Computing Surveys 38 (3): $1-24$

McAteer, E., D. Neil, N. Barr, M. Brown, S. Draper, and F. Henderson. 1996. Simulation software in a life sciences practical laboratory. Computers $\mathcal{E}^{\circ}$ Education 26 (1-3): 101-12.

Moor, S., and P. Piergiovanni. 2003. Experiments in the classroom, examples of inductive learning with classroom-friendly laboratory kits. In Proceedings of the 2003 American Society for Engineering Education Annual Conference and Exposition. Nashville, TN.

Piaget, J. 1978. The development of thought: Equilibration of cognitive structures. Oxford, England: Blackwell.

Plett, G.L., R.E. Ziemer, M.D. Ciletti, R. Dandapani, T. Kalkur, and M.A. Wickert. 2006. Experiences in updating the ECE curriculum with signal processing first and Kolb/4MAT pedagogy. In Proceedings of the 2006 American Society for Engineering Education Annual Conference and Exposition. Chicago, IL.

Raineri, D. 2001. Virtual laboratories enhance traditional undergraduate biology laboratories. Biochemistry and Molecular Biology Education 29 (4): 160-62.

Ronen, M., and M. Eliahu. 2000. Simulation — a bridge between theory and reality: The case of electric circuits. Journal of Computer Assisted Learning 16 (1): 14-26.

Roth, W.M. 1994. Experimenting in a constructivist high school physics laboratory. Journal of Research in Science Teaching 31 (2): 197-223.

Slavin, R.E. 2005. Educational psychology. Upper Saddle River, NJ: Prentice Hall.

Smith, P.R. 1976. Computers in engineering education in the United Kingdom. Computers E' Education 1 (1): 13-21.

Spicer, J.I., and J. Stratford. 2001. Student perceptions of a virtual field trip to replace a real field trip. Journal of Computer Assisted Learning 17 (4): 345-54.

Stice, J.E. 1987. Using KoIb's learning cycle to improve student learning. Engineering Education 77 (5): 291-96.

VARK. 2008. http://www.vark-learn.com/english/index.asp (last accessed October 2008).

Wankat, P.C. 2004. Analysis of the first ten years of the Journal of Engineering Education. Journal of Engineering Education 93 (1): 13-21.

Weenk, G.W.H. 1999. Learning pyramid. The Netherlands: University of Twente. 


\section{AUTHORS' BIOGRAPHIES}

Mahmoud Abdulwahed's main research interest is in the integration of IT and Cybernetics into social sciences. He is currently pursuing a $\mathrm{Ph} . \mathrm{D}$. degree at the Engineering Center of Excellence in Teaching and Learning and the Chemical Engineering Department, Loughborough University, United Kingdom.

Address: engCETL, Keith Green Building, Loughborough University, Loughborough LE11 3TU; telephone: $(+1) 44.1509$. 227189; fax: (+1) 44.1509.227181; e-mail: m.abdulwahed@ lboro.ac.uk.
Zoltan K Nagy is senior lecturer in the Chemical Engineering Department, Loughborough University since 2005. Prior to his current position Z.K. Nagy has held teaching and research positions at the University of Illinois at Urbana Champaign, USA, University of Stuttgart, Germany, ETH, Zurich, Switzerland, University of Heidelberg, Germany, and the "Babes-Bolyai" University of Cluj, Romania. Dr. Nagy is the recipient of the 2007 Royal Academy of Engineering and ExxonMobile Excellence in Teaching Award.

Address: Chemical Engineering Department, Loughborough University, Loughborough LE11 3TU, UK; telephone: $(+44)$ 1509.222516; fax: (+44) 1509.223923; e-mail: z.k.nagy@lboro.ac.uk. 


\section{APPENDIX}

\section{Questions from the Pre-lab quizzes for week I, Rigs 1-6:}

1. Describe briefly in the space provided below the key steps of the experimental procedure you plan to follow for the sensor calibration:

2. Describe briefly in the space provided below the key steps of the experimental procedure you plan to follow for the control valve calibration:

3. Define a sensor? Do we use sensors in the process? If yes, which are these?

4. Define an actuator? Do we use any actuators in the process? If yes which are these?

5. What is the functionality of the control valve in the process?

6. What do we use for measuring the inlet flow rate?

7. What do we use for measuring the outlet flow rate?

\section{Questions from the Post-Lab quiz for week I, Rigs 1-6:}

1. Analyze briefly your data obtained for the level sensor calibration. Sketch the level sensor characteristics.

2. Analyze briefly your data obtained for the control valve calibration and sketch the control valve characteristics.

3. Define the zero of a sensor. What was the zero value of the level sensor obtained based on your experiments?

4. Provide a brief definition of the term controller.

5. What is the controller when the process is set to the manual mode?

6. What is the controller when the process is set to the automatic mode?

7. Is the following an open or closed system? Explain your answer clearly.

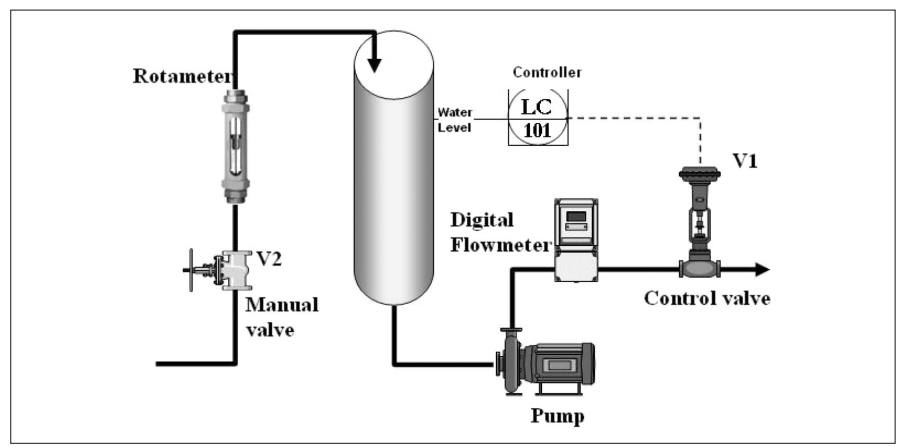

8. Is the following an open or closed system? Explain your answer clearly.

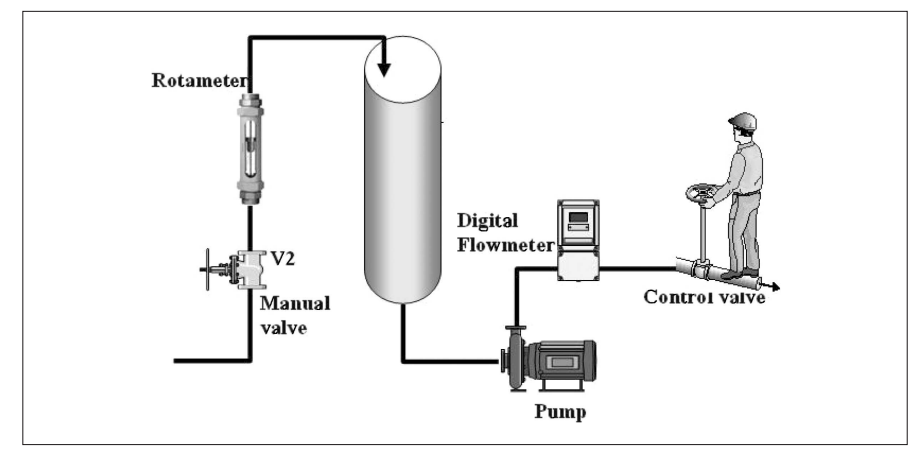

9. Is there anything wrong in the following diagram? If yes, make the necessary corrections on the figure below.

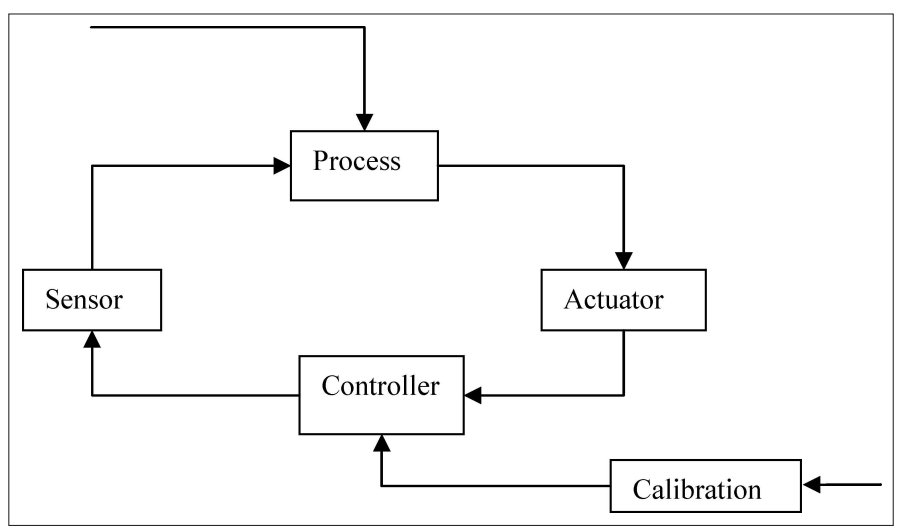

10. Based on your answer in the previous question, please place the following signals in the correct places.
a. Controller output
b. Disturbance
c. Process output
d. Controller input
e. Process input
f. Desired output value 